\title{
OPTIMIZING HOTEL BOOKING THROUGH Simulation MODELING
}

\author{
STETSENKO, D. \& KAPITANOV, V.
}

Abstract: The goal of the project is to optimize, implement and analyze the usage of simulation models in hotel bookings, and its particular economic efficiency. The key steps for achieving a functional system, the Austrian hotel market has been reviewed, various similar simulation models were studied and a new simulation technique was created and applied. After applying the simulation model to a given hotel, the results were collected and reviewed.

Key words: hotel capacity, double booking, simulation modeling, risk management
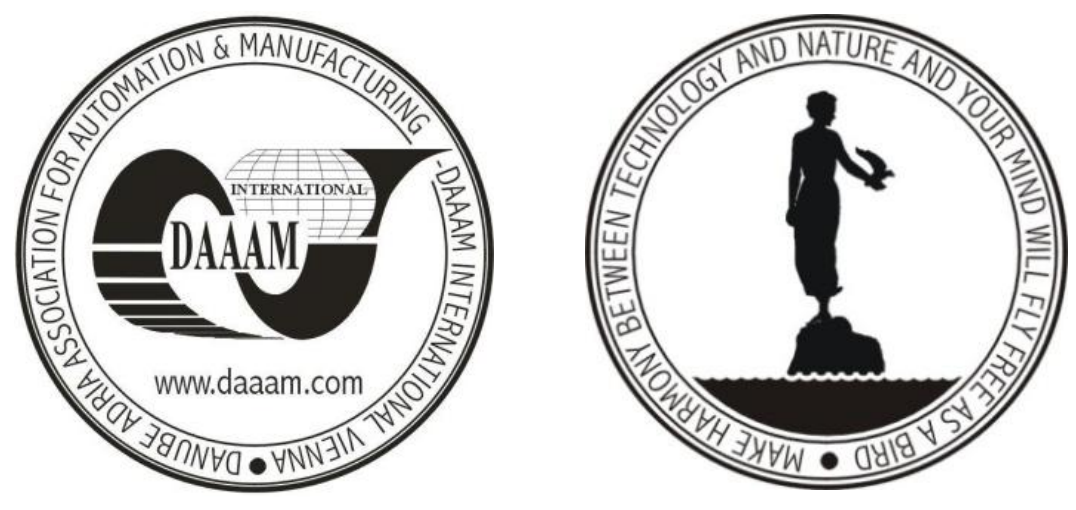

Authors' data: Stetsenko, D[mitry]*; Prof. Kapitnaov, V[alerij]**, *MODUL University, Am Kahlenberg 1a, 1190, Vienna, Austria, **National Police Department of Russian Federation, Snaipersakya street, 6, dmit.stetsenko@yandex.ru, valerij47-k@yandex.ru

This Publication has to be referred as: Stetsenko, D[mitry] \& Kapitnaov, V[alerij] (2013) Optimizing Hotel Booking Through Simulation Modelling, Chapter 58 in DAAAM International Scientific Book 2013, pp. 941-950, B. Katalinic \& Z. Tekic (Eds.), Published by DAAAM International, ISBN 978-3-901509-94-0, ISSN 17269687, Vienna, Austria

DOI: $10.2507 /$ daaam.scibook.2013.58 
Stetsenko, D. \& Kapitanov, V.: Optimizing Hotel Booking Through Simulation Mo...

\section{Introduction}

Tourism has an important part in the economical structure of many countries around the world, including Austria, where tourism is considered as very developed and profitable. If one will take a look at the touristic business in Austria, a special role here is devoted to the hotel industry, with small hotels (up to 45 rooms) being the largest group. In this case, $24 \%$ of the seats accounted for 4-5 star hotels, $20 \%$ - for three-star hotels, $18 \%$ for apartments and $11 \%$ - to 1-star hotels (WKO, 2012).

The specificity of a hotel is that if the opportunity to sell a room is missed, it is lost forever. Hotels do everything possible to fill the availability in advance and as early as possible.

Large hotels have the advantage of providing empty rooms for various events e.g. workshops, festivals and conferences that require a reservation. Rooms that are not booked in advance shall be submitted for direct sale at the reception, the duty of which is to sell the service to as many customers at the highest price.

The demand for hotel services is unevenly distributed throughout the year. At certain times it exceeds supply, which forces some of the hotels to use the so-called tactic of double booking (booking is approved even if no rooms are available). The hotel goes for a risk, focusing on the approximate level of predictable failure of the reservation. This tactic means that the hotel is not willing to miss out on potential profits, knowingly risking paying the penalty for refusing to accommodate guests. In some cases, hotels that are concerned about not losing a customer, offer more expensive rooms at a discount price.

Identifying the major trends in the development of any process allows planning for the possible values of its parameters in order to form a system of measures and ensure achievement of the goal.

Decision-making process means to determine what the management should be in order to achieve control objectives of a specified task. Typically, the solution is based on an existing model (mathematical representation) of an object, a given target, the information about the state of the environment as well as dedicated resource management, which is most often a restriction imposed on the administration in connection with the specific features of the object and control system (time, material etc.).

In this article, solutions to optimize management capacity of the hotel are proposed, which allow decisions to provide expensive rooms at lower prices.

\section{Literature Review}

Simulation process is an instrument for managing change (Barnett, 2003). It is critical for organizations to carefully lead its business from traditional to new ways of operating. A simulation appears to be one way to accelerate such change. The potential is mainly taken out from the capability of a simulation to bring accuracy to the reasons for change. Moreover, a simulation provides more than an answer: it shows how the answer was carried out. The process enables a specific organization to generate explanations for decisions.

When developing a simulation model, three elements are identified: the parts of the system, the interaction between the parts as well as the number and nature of 
inputs. A model is created for each of these, with critical factors considered and minor factors ignored. Consequently, the simulation model for the whole system is developed (Feinstein \& Parks, 2002).

Most of the simulation theories in the 1990s were addressed towards specific hospitality operational problems: A literature review that was focused on the integration of information technology, service quality, and new organization structures was prepared (Durocher and Niman, 1993). This evaluation provided an interesting framework for future empirical testing on simulation models: labor requirements (Godward and Swart, 1994); cafeteria modeling (Stout, 1995); simulation of drive-through and lobby management (Farahmand and Martinez, 1996) and on buffet management (Field et al., 1997).

The most recent is the simulation model for forecasting hotel arrivals and occupancy by using the Monte Carlo simulation (Zakhary et al., 2009). The major idea behind that simulation model was to focus on and support the revenue management system of a hotel. The hotel reservation process was simulated forward in time and the Monte Carlo simulation paths would yield forecast densities. Reservation arrivals, cancelations, length of stay, no shows, group reservations, seasonality, trend and etc. were simulated during the research process.

This article contains a presentation of a different simulation model, created by the authors and will be focusing on reducing risks connected to the booking process for a specific small business hotel in the Austrian Republic.

\section{Methodology}

Approximately efficient frontier of better (more expensive) rooms at the desired employment (cheaper) can be estimated on the basis of the following assumptions for the simplest case:

- all channels (hotel rooms) of the same type;

- the input of the $\mathrm{n}$ - channel (number of rooms) system comes Poisson process with intensity applications $\lambda$;

- the intensity of the Poisson flow of service of each channel (number) ${ }^{\mu}$;

- if the application has found all the channels (numbers) occupied, it leaves the system unserved;

- if the application has found at least one free channel (room), it is accepted to service any of the free channels (rooms).

This assumption enables to use the well-known model of queuing theory. formula:

Under this model, the probability $P_{0}$ of service requests is determined by the

$$
\begin{gathered}
P_{o}=\frac{R(n-1, \alpha)}{R(n, \alpha)} \\
\text { Where } \alpha=\frac{\lambda}{\mu}
\end{gathered}
$$




$$
R(n, \alpha)=\sum_{k=0}^{n} \frac{\alpha^{k}}{k !} e^{-\alpha}-\text { table function of the Poisson distribution }
$$

These relations can be generalized to the case of hotels with rooms ${ }^{n}$-types.

The essence of the problem is to determine how much of it is advisable to redirect the flow of customers into more expensive rooms (at the price of a cheap room) in order to get the most income.

The boundary of this part of the feasibility of redirecting the flow of customers (at high load ordered rooms) in more expensive rooms are approximate, based on the condition that it shall be ensured increase (per unit time) of the total value of given rooms:

$$
\begin{gathered}
\sum_{i=1}^{n} \bar{c}_{i} \frac{R\left(n_{i}-1, \frac{\lambda_{i}-\delta_{i}+\overline{\delta_{i}}}{\mu_{i}}\right)}{R\left(n_{i}, \frac{\lambda_{i}-\delta_{i}+\bar{\delta}_{i}}{\mu_{i}}\right)}\left(\lambda_{i}-\delta_{i}+\overline{\delta_{i}}\right) \geq \sum_{i=1}^{n} c_{i} \frac{R\left(n_{i}-1, \frac{\lambda_{i}}{\mu_{i}}\right)}{R\left(n_{i}, \frac{\lambda_{i}}{\mu_{i}}\right)} \lambda_{i}(i=2, \ldots, n) \\
\overline{c_{i}}=\frac{c_{i}\left(\lambda_{i}-\delta_{i}\right)+\sum_{j=1}^{i-1} c_{j} \delta_{j}}{\lambda_{i}+\sum_{j=1}^{i-1} \delta_{j}-\delta_{i}}(i=2, \ldots, n) \\
\forall i: \lambda_{i} \geq \sum_{j=i+1}^{n} \delta_{i j}(i=2, \ldots, n) \\
P_{o}=\frac{R(n-1, \alpha)}{R(n, \alpha)}(i=1, \ldots, n-1)
\end{gathered}
$$

Where ${ }^{c_{i}}$ - price for a room ${ }^{i}$-type;

$\lambda_{i-}$ the flow of customers into the rooms of the $i_{\text {-type; }}$

$\mu_{i}$ - room service rate ${ }^{i}$-type;

$n_{i}$ - number of rooms ${ }^{i}$-type;

$\delta_{i}$ - intensity redirected (in the more expensive rooms) customer flow of the rooms ${ }^{i}$-type;

$\overline{\delta_{i}}$ - intensity redirected (entering) the flow of customers (of the cheaper rooms) in numbers $i$-type;

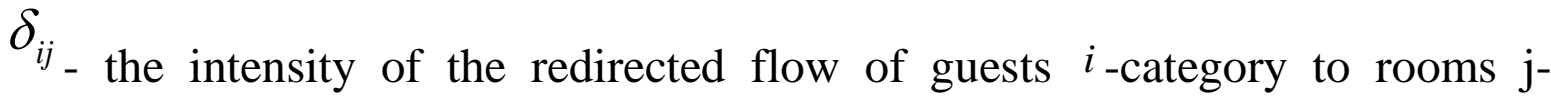
category. 
Let the hotel rooms are available in two types. In this case, the inequality can be written as:

$$
\begin{aligned}
& \frac{R\left(n_{1}-1, \frac{\lambda_{1}-\delta_{1}}{\mu_{1}}\right)}{R\left(n_{1}, \frac{\lambda_{1}-\delta_{1}}{\mu_{1}}\right)}\left(\lambda_{1}-\delta_{1}\right) c_{1}+\frac{R\left(n_{2}-1, \frac{\lambda_{2}+\delta_{1}}{\mu_{2}}\right)}{R\left(n_{2}, \frac{\lambda_{2}+\delta_{1}}{\mu_{2}}\right)}\left(c_{1} \delta_{1}+c_{2} \lambda_{2}\right) \geq \\
& \frac{R\left(n_{1}-1, \frac{\lambda_{1}}{\mu_{1}}\right)}{R\left(n_{1}, \frac{\lambda_{1}}{\mu_{1}}\right)} \lambda_{1}+\frac{R\left(n_{2}-1, \frac{\lambda_{2}}{\mu_{2}}\right)}{R\left(n_{2}, \frac{\lambda_{2}}{\mu_{2}}\right)} \lambda_{2}, \\
& \lambda_{1} \geq \delta_{1} .
\end{aligned}
$$

The calculation requires the following data:

$\lambda_{i_{-}}$the flow of customers into the rooms of the $i_{\text {-type; }}$

$\mu_{i}$ - the reciprocal of the mean residence time in the room ${ }^{i}$-type hotel;

$n_{i}, c_{i}$ - accordingly, the number of rooms and accommodation $i_{\text {-type; }}$

Border - equality mentioned in the above expression.

Figure 1 shows typical plots (relating to the same object with two types of rooms) according to the total value of $\mathrm{C}$ from room handed intensity $\mathrm{d}=\delta_{1}$ the redirected stream. The analysis showed that in a sufficiently large range of the input data it is possible to improve the efficiency of room stock (series 1 in Fig. 1).

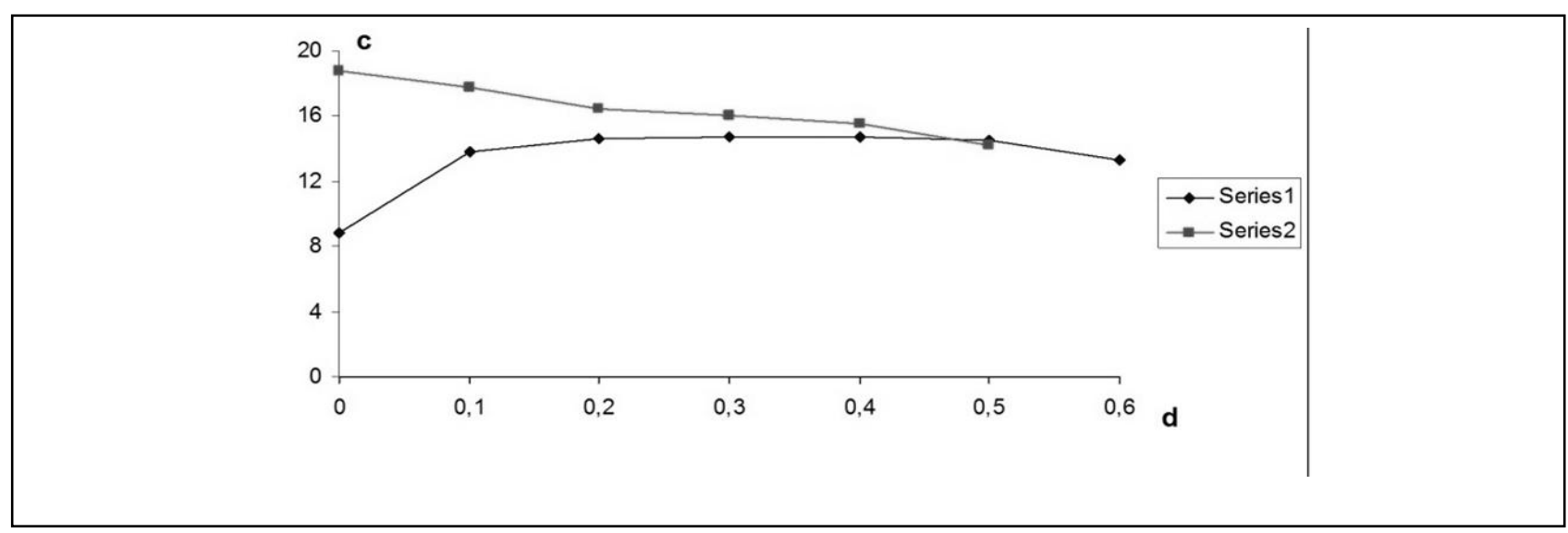

Fig. 1. Plots of the total value of $\mathrm{C}$ surrendered rooms on the intensity of $\mathrm{d}=$ redirects

The task of determining the optimal (maximum) load hotel (the model) is formulated in the form of:

$$
\sum_{i=1}^{n} \overline{c_{i}} \frac{R\left(n_{i}-1, \frac{\lambda_{i}-\delta_{i}+\overline{\delta_{i}}}{\mu_{i}}\right)}{R\left(n_{i}, \frac{\lambda_{i}-\delta_{i}+\overline{\delta_{i}}}{\mu_{i}}\right)}\left(\lambda_{i}-\delta_{i}+\overline{\delta_{i}}\right) \underset{\delta_{i} \bar{\delta}_{i}}{\rightarrow} \max
$$


Stetsenko, D. \& Kapitanov, V.: Optimizing Hotel Booking Through Simulation Mo...

$$
\begin{gathered}
\overline{c_{i}}=\frac{c_{i}\left(\lambda_{i}-\delta_{i}\right)+\sum_{j=1}^{i-1} c_{j} \delta_{j}}{\lambda_{i}+\sum_{j=1}^{i-1} \delta_{j}-\delta_{i}}(i=2, \ldots, n) \\
\overline{\delta_{i}}=\sum_{j=1}^{i-1} \delta_{j}(i=2, \ldots, n), \\
\forall i: \lambda_{i} \geq \sum_{j=i+1}^{n} \delta_{i j} \\
\delta_{i}=\sum_{j=i+1}^{n} \delta_{i j}(i=1, \ldots, n-1)
\end{gathered}
$$

The solution of the problem can be obtained by brute-force values $\delta_{i}, \overline{\delta_{i}}$. The resulting solutions can be specified as part of the simulation model, which is understood as a step by step modeling of the object being studied using a computer (scan time).

As it is known, simulation is the study of complex systems, aimed at obtaining information about the system itself. To simulate means to experiment with the model of the real object (model experiment), where a PC serves as a research tool.

Certain fixed points in time and description of the state of the object are calculated consistently in each of the time points. This process requires a set of rules in accordance with which the transition from one state to another object.

It is essential that there is a possibility of estimating the statistical properties of the object (model). For this purpose, a random number is generated.

The following model of service requests for reservation of hotel rooms is based on the methods of simulation is and aimed at improving the quality of operation of the hotel business.

Distribution of random variables is formed on the basis of pseudo-random numbers generated by deterministic algebraic formulas. In practice, stated that pseudo-random number is uniformly distributed in the interval $(0,1)$ and independent.

In the model experiment special values studied characteristics are received. Simulation makes a functional relationship between these characteristics with the independent variables and parameters (as was the case for the above model of queuing theory). Therefore it is required to perform calculations with one or more sets of parameter values. This means that in case of a need to obtain optimal solutions on the basis of simulation (stochastic) models, certain amount for the model of experimental studies of various sets of parameters and variables is needed. The initial random number is taken from the system clock (initialized with random values embedded random number generator).

In this case, actual statistical sampling experiment with a model of the system is produced. Each set of parameter values and the independent variables of the object 
correspond to the sample (monitor) a certain volume. The sample size affects the "statistical reliability" evaluated the response of the simulated object.

Figure 2 is a schematic block diagram of a decision to book hotel rooms.

The client sends a request to the type (j). If the requested type is available, the application is accepted. If there is no available number of the requested type, then there are two possible solutions:

- refuse a guest.

- offer customers higher room category, the price requested category (the lowest category).

The second solution is allowed if:

- permitted $(\mathrm{Lu}=1)$;

The interval of time from arrival to the room request does not exceed the threshold $\mathrm{t}_{\mathrm{min}}$

There is a free room for the requested time period.

Concerning all mentioned above a simulation model of decision-making on reservations was developed. The essence of the model is as follows.

Considering carefully arbitrary hotel, where there is no (i) numbers of different types $(i=1, \ldots$, tip - the number of types). Applications received for booking of various types at random times, the intervals between which tpz distributed to the exponential (Poisson process) law. The intensity of the flow of requests $-q$.

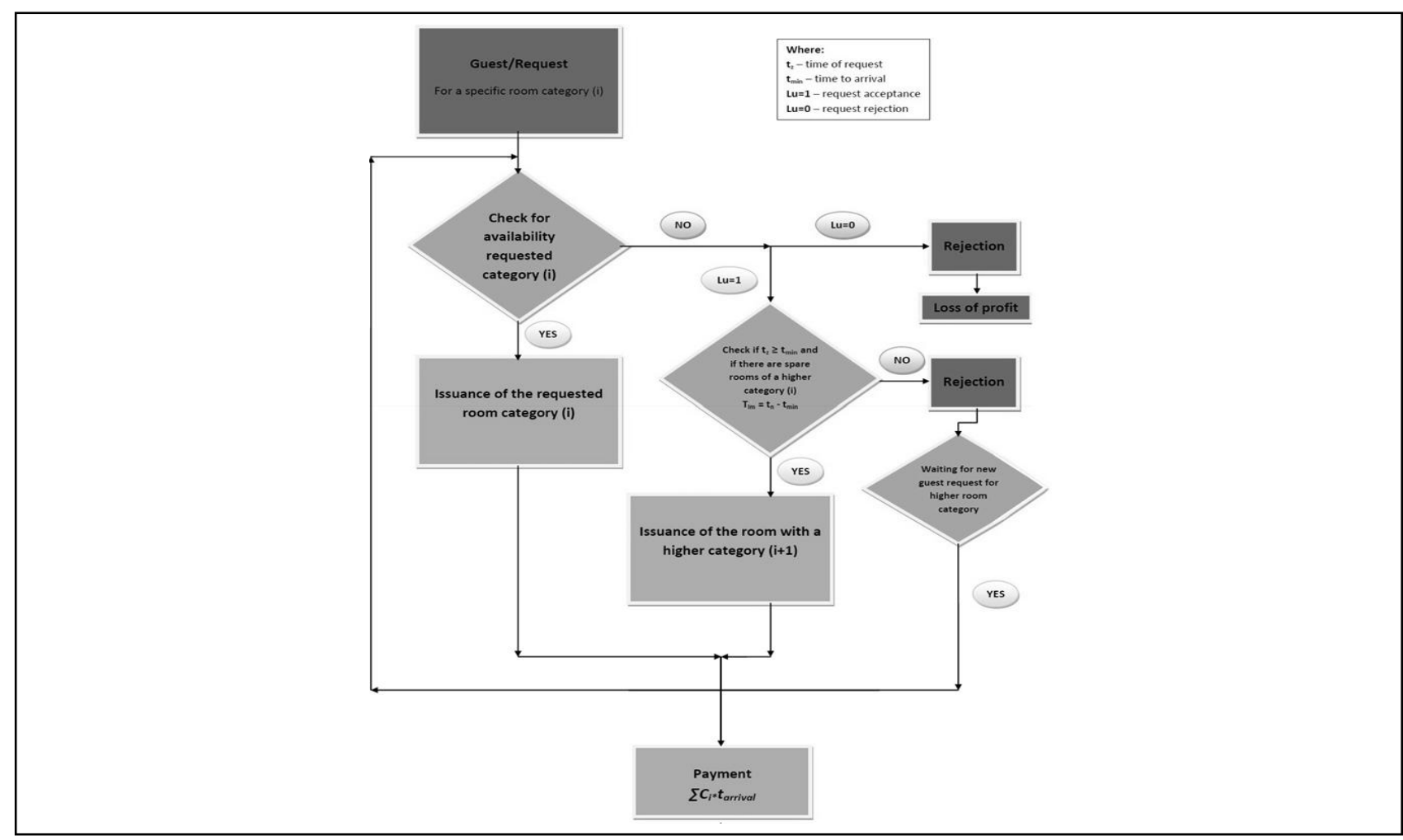

Fig. 2. A block diagram of the decision on reservations

Figure 3 illustrates the onset of events in the simulation model on the time axis (t), including - "the last moment" (Tlast moment - a time interval during which the hotel offers room upgrade). 


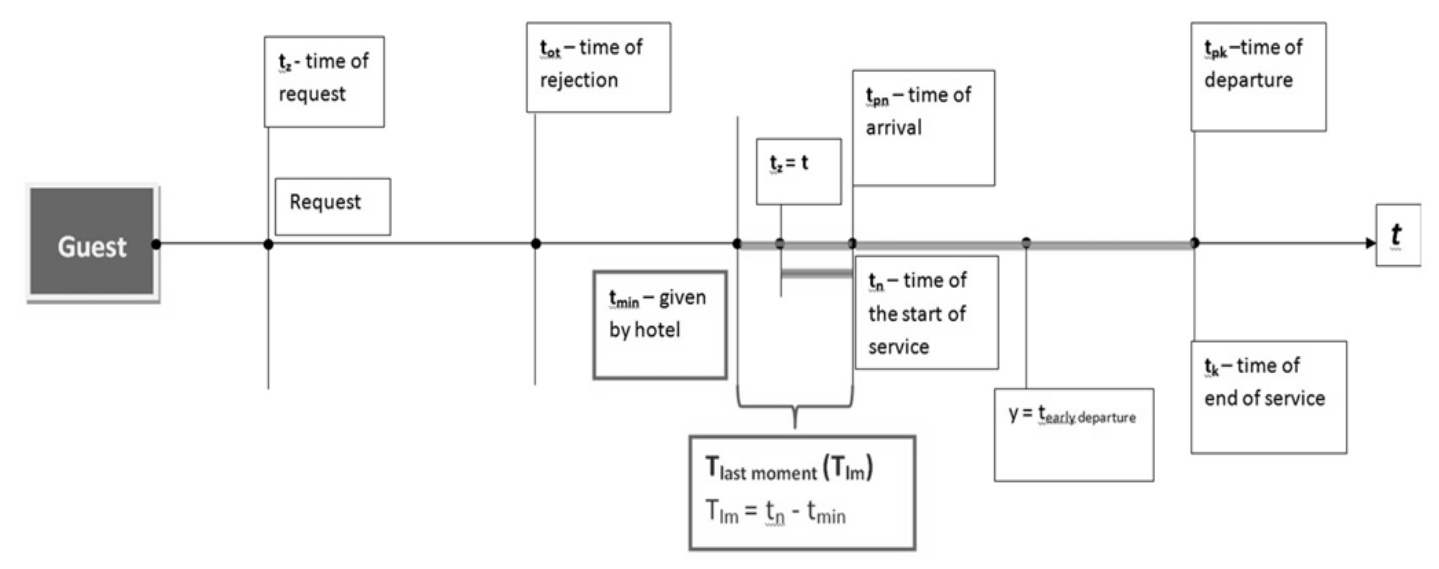

Fig. 3. The sequence of model events on the time axis

The time intervals between the receipt of applications and the arrival of exponential distribution with mean - tpo. Duration of stay in the hotel is a random variable distributed exponentially with a mean of $t p$.

Probability of a certain type of application numbers, as well as cancellation policies are uniformly distributed in the intervals ( 0 , tip), and (the time of filing, the stated time of departure from the hotel).

Initial parameters for the simulation model are following:

- The number of categories (types of rooms $)-(j=1, \ldots$, tip)

- The number of rooms of category $\mathrm{j}-(\mathrm{i}=1, \ldots$, imax $)$

- Duration of the simulation - tr

- The step of simulation - $h$

- The intensity (quantity/time) of the flow of requests - q

- The probability request room $\mathrm{j}$ - type $(\mathrm{j}=1, \ldots$, tip) - $\mathrm{p}(\mathrm{j})$

- A daily rate (price) number $\mathrm{j}$ - type $(\mathrm{j}=1, \ldots$, tip) - c $(\mathrm{j})$

- The average interval (time) stay in a hotel - tp

- The average interval (time) from application to arrival at the hotel - tpo

- The probability of rejection of the application - pot

\section{The calculation Results and the Findings}

The research shows that between 0 to 72 hours the value TLM $=48$ allows for an increase in the monthly income from the rental of hotel rooms to 7,132 (EUR) and the annual profit up to 85.588 (EUR).

The foregoing is illustrated by the data given in Table 1 and Figure 4.

Thus, it was found that under certain conditions (the rate of requests, quantitative number of rooms, etc.) it is possible to increase profits at the expense of the hotel redirection of the flow of customers requesting the cheapest rooms in more expensive rooms (at the price of a cheap room). In this case, additional capital expenditures for profit is not required, but it is necessary for each hotel to collect baseline information and perform the necessary calculations. 


\begin{tabular}{|c|c|c|c|c|}
\hline Tlast moment & Profit (sum) & Profit (h) & $\begin{array}{l}\text { Profit (sum) } \\
\text { average }\end{array}$ & Profit (h) average \\
\hline \multirow[t]{5}{*}{$\mathrm{Oh}$} & 80353 & 111 & & \\
\hline & 85353 & 118 & & \\
\hline & 75555 & 104 & 81110 & 112 \\
\hline & 81972 & 113 & & \\
\hline & 82317 & 114 & & \\
\hline \multirow[t]{5}{*}{$24 \mathrm{~h}$} & 87631 & 121 & & \\
\hline & 84525 & 117 & & \\
\hline & 87906 & 122 & 85394,6 & 118,2 \\
\hline & 80316 & 111 & & \\
\hline & 86595 & 120 & & \\
\hline \multirow[t]{4}{*}{$48 \mathrm{~h}$} & 88321 & 122 & & \\
\hline & 89079 & 123 & & \\
\hline & 87354 & 121 & 88142,4 & 121,8 \\
\hline & 87633 & 121 & & \\
\hline
\end{tabular}

Tab. 1. The dependence of the profits from the Tlm (last minute)

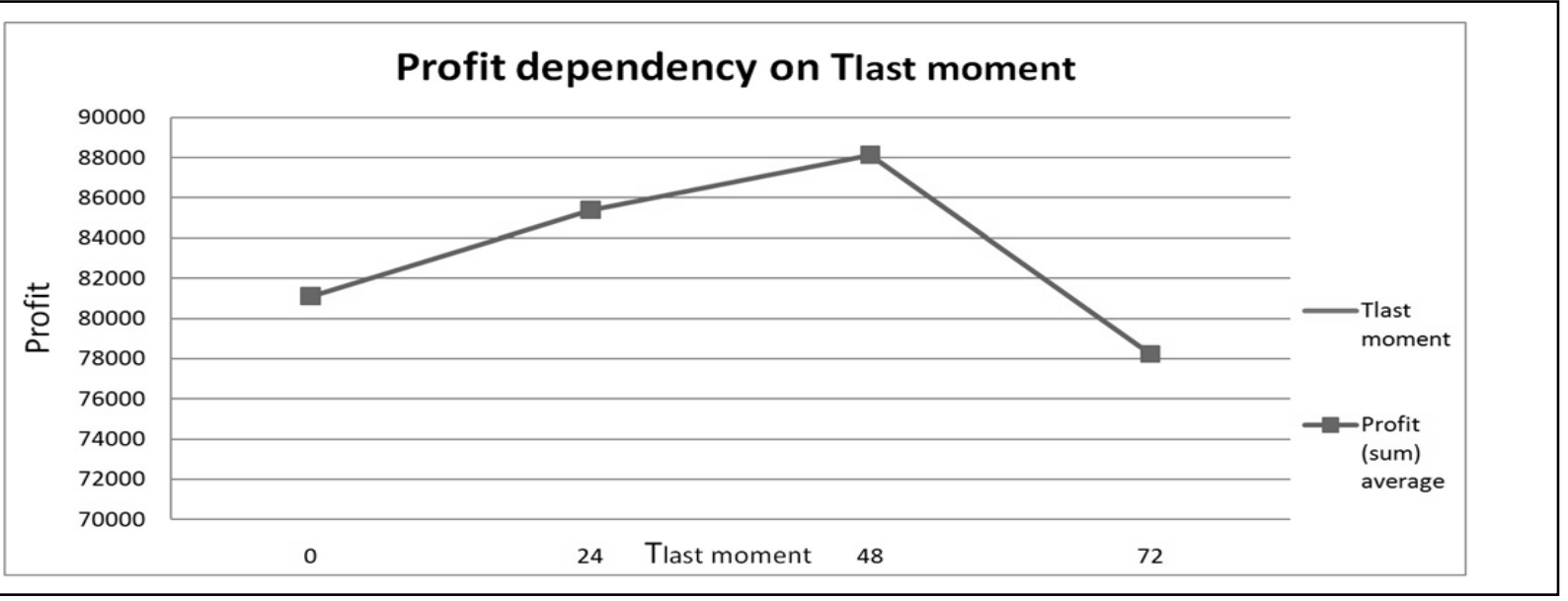

Fig. 4. The dependence of the profits from the Tlm (last minute)

\section{Conclusion}

The problem discussed in the article is following: in some situations, where the demand for accommodation in certain periods of time is higher than the supply, some hotels will make a double booking - the booking will be confirmed, even when there are no free rooms available. Placement staff is taking risks, focusing on the approximate level of the predictable rejections of the reservation. Thus, seeking to maximize revenue, the hotel is uncertain when balancing between incomplete and double booking rooms. In the first case the hotel misses the opportunity to maximize profits, and the second - is forced to pay a penalty for refusing rejection to place the guest.

By applying the presented simulation model, the risk of losing additional profit can be calculated for various small- and medium-sized hotels for certain seasons. As shown on the "***" hotel, the necessary steps to achieve optimization are: 1) input of simulation parameters (the rate of requests, quantitative number of rooms, etc.), 2) execution of the computer program, 3) analysis of the output (profit, number of rooms reserved/not reserved, probability of occupancy for each room category, 
Stetsenko, D. \& Kapitanov, V.: Optimizing Hotel Booking Through Simulation Mo...

probable average length of stay, number of early check-outs, profit/hour) and 4) drawing conclusions from given results. The implementation of such system allows for reduced risks while booking rooms.

The results obtained from the experiment are as follows: ranging between 0 and 72 hours, the best revenue optimum for the specified hotel is before two days, allowing an increase in the monthly income from the rental of hotel rooms to 7,132 (EUR) and the annual profit up to 85.588 (EUR).

For future research, the simulation model will be improved using consumer feedback. Furthermore, the Semmering region situates five more hotels with identical parameters as the researched "Sonnwendhof***" hotel. Consequently, it is vital to estimate the efficiency of the simulation model and apply it to the rest of the hotels available in order to improve their management.

\section{References}

Barnett, M. W. (2003). Modeling \& simulation in business process management. Gensym Corporation

Durocher, J.F. \& Niman, N.B. (1993). Information technology: management effectiveness and guest services. Hospitality Research Journal 1993, Vol. 17, No. 1, pp. 121-131, ISSN

Farahmand, K. \& Martinez, A.F. (1996). Simulation and animation of the operation of a fast food restaurant. Proceedings of the 1996 Winter Simulation Conference, pp. 1264-1271, ISBN, in J.M. Charnes, D.J. Morrice, D.T. Brunner, and J.J. Swain (Eds.) Feinstein, A. H. \& Parks, S. J. (2002). Simulation Research in the Hospitality Industry. Developments in Business Simulation and Experiential Learning, Vol. 29, Pensacola, FL, USA

Field, A.; McKnew, M. \& Kiessler, P. (1997). A simulation comparison of buffet restaurants: applying Monte Carlo modeling. The Cornell Hotel and Restaurant Administration Quarterly, December, 68-79

Godward, M. \& Swart W. (1994). An object oriented simulation model for determining labor requirements at Taco Bell. Proceedings of the 1994 Winter Simulation Conference, pp. 1067-1073, in J. D. Tew, S. Manivannan, D.A. Sadowski, \& A.F. Seila (Eds.)

Stout, W.A., Jr. (1995). Modeling a hospital main cafeteria. Proceedings of the 1995 Winter Simulation Conference, pp. 1060-1065, in C. Alexopoulos, K. Kang, W.R. Lilegdon \& D. Goldsman (Eds.)

WKO (2012). TOURISMUS IN ZAHLEN. Österreichische und Internationale Tourismus- und Wirtschaftsdaten, 48. Ausgabe, Mai 2012.(Austrian Chamber of Commerce (2012). TOURISM IN NUMBERS. Austrian and international Tourism and Commercial data, Vol. 48, May 2012)

Zakhary A.; Atiya A. F.; El-Shishiny H. \& El Gayar N. (2009). Forecasting Hotel Arrivals and Occupancy using Monte Carlo Simulation. Cairo University, IBM Cairo Technology Devepment Center, Nile University, Giza, Egypt, April 17, 2009 